\title{
ANALISIS RESIDU PESTISIDA KLORPIRIFOS PADA BERAS (Oryza sativa) YANG BERASAL KECAMATAN BAEBUNTA KABUPATEN LUWU UTARA
}

\author{
Nurjannah, Risfah Yulianty, Asnah Marzuki, Syaharuddin Kasim, Nana Juniarti Natsir Djide \\ Fakultas Farmasi, Universitas Hasanuddin, Makassar, Indonesia
}

Kata Kunci :

Beras, residu pestisida, klorpirifos, GC/MS, BMR

\begin{abstract}
ABSTRAK
Penggunaan pestisida di Indonesia sudah merupakan bagian yang tidak terpisahkan dalam sistem pertanian. Klorpirifos merupakan salah satu kelompok pestisida golongan organofosfat yang banyak digunakan untuk membunuh berbagai serangga. Adanya residu klorpirifos dapat menyebabkan gangguan kesehatan sehingga deteksi residu klorpirifos dalam produk pangan merupakan hal yang penting. Penelitian ini dilakukan untuk mengetahui kadar residu klorpirifos pada beras yang berasal dari Kecamatan Baebunta, Kabupaten Luwu Utara dan keamanannya untuk dikonsumsi. Sampel beras diambil langsung dari beberapa petani di Kecamatan Baebunta, Kabupaten Luwu Utara. Sampel diekstraksi dan di clean-up menggunakan metode QuEChERS dan dianalisis menggunakan GC/MS. Kadar residu klorpirifos dibandingkan dengan standar Batas Maksimum Residu (BMR)pada SNI. Hasil penelitian menunjukkan bahwa residu klorpirifos pada sampel A, B dan C masing-masing sebesar 0,133; 0,092; dan 0,308 mg/kg. Dengan demikian, beras yang berasal dari Kecamatan Baebunta Kabupaten Luwu Utara memiliki kadar residu di bawah nilai BMR $(0,5 \mathrm{mg} / \mathrm{kg})$ sehingga aman untuk dikonsumsi.
\end{abstract}

\section{PENDAHULUAN}

Beras merupakan komoditi utama yang banyak digunakan masyarakat Indonesia.Konsumsi beras per kapita di Indonesia pada tahun 2017 tercatat hampir $150 \mathrm{~kg}$ (beras, per orang, per tahun). Tingkat konsumsi ini melebihi tingkat konsumsi beras dunia yang berkisar $80-90 \mathrm{~kg} / \mathrm{kapita} / \mathrm{tahun}$ (1). Oleh karena itu, peningkatan produksi beras terus diupayakan untuk mengimbangi kenaikan konsumsi mengingat petumbuhan jumlah penduduk Indonesia yang masih tinggi.Salah satu upaya untuk meningkatkan produksi padi yaitu dengan menggunakan pestisida yang dari tahun ke tahun semakin meningkat (2).

Penggunaan pestisida di Indonesia dewasa ini sudah merupakan bagian yang tidak terpisahkan dalam sistem pertanian. Penggunaan pestisida kimia merupakan sarana pengendali organisme pengganggu tanaman (OPT) yang paling banyak digunakan oleh petani di Indonesia (95,29\%) karena dianggap efektif, mudah digunakan dan secara ekonomi menguntungkan. Besarnya manfaat pestisida yang dirasakan oleh petani menyebabkan petani memiliki ketergantungan yang tinggi pada pestisida, semakin banyak pestisida yang digunakan maka semakin baik karena produksi pertanian semakin meningkat. Penggunaan pestisida yang berlebihan dapat mencemari lingkungan dan meninggalkan residu pestisida pada produk pertanian yang dapat menimbulkan masalah kesehatan $(3,4)$

Salah satu golongan pestisida yang banyak digunakan oleh petani adalah pestisida golonganorganofosfat. Pestisida organofosfat menimbulkanefek pada serangga, mamalia, dan manusia melalui penghambatan asetilkolinesterase, sehingga terjadi penumpukan asetilkolin yang mengakibatkan terjadi kekacauan sistem pengantar impuls saraf ke sel-sel otot. Beberapa gejala keracunan pestisida organofosfat yaitu sakit kepala, pusing, mual, muntah, pupil mengecil sehingga pengelihatan menjadi kabur, air liur berlebih, keringat berlebih, detak jantung sangat cepat dan otot tidak dapat digerakkan (5).

Salah satu golongan organofosfat yang banyak digunakan masyarakat di kecamatan Baebunta yaitu klorpirifos. Pestisida ini biasanya dipasarkan dengan merek dagang Lorsban ${ }^{\circledR}$ dan Dursban ${ }^{\circledR}$. Batas maksimum residu (BMR) klorpirifos yang diperbolehkan oleh Standar Nasional Indonesia (SNI) pada beras adalah 0,5 mg/kg (6). Berdasarkan hasil survei yang dilakukan pada petani di kecamatan Baebunta, klorpirifos diaplikasikan dengan cara disemprotkan pada buah padi sebanyak 2-3 kali sekitar 25-30 hari menjelang panen. Adanya pengaplikasian pestisida ini pada buah padi menjelang panen memungkinkan adanya residu pestisida yang tertinggal yang dapat membahayakan kesehatan manusia.

Berdasarkan permasalahan di atas, maka dilakukan penelitian untuk mengetahui apakah kadar residu pestisida klorpirifos di Kecamatan Baebunta, Kabupaten Luwu Utara tidak melebihi BMR yang ditetapkan oelh SNI sehingga aman untuk dikonsumsi. 


\section{Pengambilan Sampel}

Sampel yang digunakan yaitu beras (Oryza sativa). Sampel diperoleh dari beberapa petani dari Kecamatan Baebunta, Kabupaten Luwu Utara, Provinsi Sulawesi Selatan.

\section{Preparasi Sampel dan Pembuatan Larutan Uji}

Penelitian ini dilakukan di Balai Proteksi Tanaman Pangan Hortikultura (BPTPH) yang berlokasi di Maros.Preparasi sampel dilakukan dengan metode QuEChERS.Sampel beras masing-masing dicuci dan dihaluskan menggunakan blender. Sampel yang telah dihaluskan ditimbang sebanyak $5 \mathrm{~g}$ dalam tabung sentrifus, ditambahkan $10 \mathrm{~mL}$ aquades dan $15 \mathrm{~mL}$ asetonitril, kocok kuat agar tercampur rata. Sebanyak $6 \mathrm{~g}$ $\mathrm{MgSO}_{4}$ anhidrat dan 15 g natrium asetat anhidrat dimasukkan ke dalam tabung sentrifus, kocok dengan tangan selama 1 menit kemudian sentrifugasi selama 1 menit dengan kecepatan $3700 \mathrm{rpm}$. sebanyak 6-8 mL supernatan diambil dan dimasukkan ke dalam tabung sentrifus yang mengandung $150 \mathrm{mg} \mathrm{MgSO}_{4}$ anhidrat, $50 \mathrm{mg}$ PSA, dan $50 \mathrm{mg}$ $\mathrm{C}_{18}$ kemudian kocok kembali selama 1 menit dan sentrifugasi selama 1 menit dengan kecepatan $3700 \mathrm{rpm}$. Sebanyak 1,5 $\mathrm{mL}$ supernatan diambil untuk dianalisis menggunakan GC/MS (7)

\section{Pembuatan Larutan Standar}

Larutan standar klorpirifos dibuat dari standar yang telah ada sebelumnya yaitu klorpirifos $1000 \mathrm{mg} / \mathrm{L}$ (1000 ppm). Dari larutan stok dibuat pengenceran 0,$5 ; 0,75$ dan 1 ppm dengan menggunakan pelarut asetonitril.

\section{Pengukuran Kadar Residu Klorpirifos dengan Instrumen GC/MS}

Larutan standar dan larutan uji dianalisi menggunakan instrumen CG/MS dengan volume injeksi $1 \mu \mathrm{L}$, gas pembawa helium, suhu oven $100^{\circ} \mathrm{C}$, suhu injeksi $280^{\circ} \mathrm{C}$, model injeksi splitless dengan waktu pengoperasian diatur selama 13 menit.

\section{Analisis Data}

Data yang diperoleh berupa gambar kromatogram waktu retensi $\left(t_{R}\right)$ dan luas area dari kromatogram sampel dikumpulkan dan dianalisis.

\section{HASIL DAN PEMBAHASAN}

Sampel beras pada penelitian ini diekstraksi dengan metode QuEChERS (Quick, Easy, Cheap, Effective, Rugged and Safe) dengan beberapa keunggulan seperti tahapan analisis mudah dan efektif pada proses clean up, selain itu juga ramah lingkungan karena menggunakan sedikit pelarut organik, jika dibandingkan dengan metode ekstraksi lainnya seperti metode maserasi yang membutuhkan banyak pelarut dan waktu yang cukup lama (8).

Proses ekstraksi diawali dengan penambahan air sebagai pembasah yang bertujuan untuk menghidrasi sampel, melemahkan interaksi pestisida dengan komponen matriks dan membantu efisiensi pada proses ekstraksi. Selanjutnya ditambahkan asetonitril sebagai pelarut dikarenakan memiliki jangkauan polaritas yang luas bagi residu pestisida dibandingkan dengan aseton dan etil asetat. Selain itu, asetonitril mudah dipisahkan dengan air. Sedangkan penggunaan $\mathrm{MgSO}_{4}$ anhidrat berfungsi untuk memisahkan air dari sampel (8).

Setelah proses ekstraksi dilakukan proses clean-up dengan menggunakan Primary Secondary Amine (PSA) dan $\mathrm{MgSO}_{4}$ anhidrat. PSA merupakan bahan penyerap atau sorben penukar anion yang lemah, yang dapat menghilangkan beberapa matriks karena mengandung amino primer dan sekunder. PSA berinteraksi dengan bahan kimia oleh hidrogen mengikat dan menghilangkan senyawa sejenis seperti asam lemak, asam organik, pigmen polar, sebagian gula dan asam lemak. Sedangkan $\mathrm{MgSO}_{4}$ anhidrat berfungsi untuk menghilangkan air yang masih tertinggal pada larutan. Hasil yang diperoleh dari proses clean-up yaitu larutan yang lebih jernih dibandingkan dengan hasil ekstraksi (8).

Pembuatan kurva standar dilakukan dengan meregresikan konsentrasi dan luas area. Dari hasil regresi diperoleh persamaan linear $y=4198.6 x-114.81$ dengan koefisien korelasi $\left(\mathrm{r}^{2}\right)$ sebesar 0,9945 .

\begin{tabular}{ccc}
\multicolumn{3}{c}{ Tabel 1. Waktu retensi dan area kromatogram pada sampel beras } \\
\hline Sampel & Waktu retensi & Area \\
\hline \multirow{2}{*}{ A } & 6,215 & 37 \\
& 6,210 & 113 \\
\hline \multirow{2}{*}{ B } & 6,218 & 26 \\
& 6,218 & 19 \\
\hline \multirow{2}{*}{ C } & 6,210 & 397 \\
& 6,207 & 244 \\
\hline
\end{tabular}

Tabel 1. Waktu retensi dan area kromatogram pada sampel beras

\begin{tabular}{ccc}
\hline Sampel & $\begin{array}{c}\text { BMR Klorpirifos } \\
(\mathbf{m g} / \mathbf{k g})\end{array}$ & $\begin{array}{c}\text { Kadar Residu Rata- } \\
\text { rarta (mg/kg) }\end{array}$ \\
\hline A & & 0,133 \\
B & 0,5 & 0,095 \\
C & & 0,308 \\
\hline
\end{tabular}

Berdasarkan Tabel 2. diketahui bahwa ketiga sampel memiliki kadar residu klorpirifos pada beras tidak lebih dari BMR yang ditetapkan oleh SNI 2008 yaitu $0,5 \mathrm{mg} / \mathrm{kg}$, sehingga dapat disimpulkan bahwa ketiga sampel yang berasal dari kecamatan Baebunta kabupaten Luwu Utara aman untuk dikonsumsi.

Kadar residu pestisida dari ketiga sampel memiliki kadar yang berbeda, hal ini disebabkan adanya perbedaan perlakuan dari masing-masing petani, baik dari waktu, cara, seta frekuensi penyemprotan pestisida pada tanaman padi. Selain itu, preparasi sampel serta teknik pengerjaan juga dapat mempengaruhi hasil analisis kadar klorpirifos. Pencucian dengan air dapat menghilangkan residu pestisida yang ada di permukaan sampel. Pencucian beras dengan air dapat menghilangkan kira-kira $60 \%$ dari residu klorpirifos (9).

Frekuensi penyemprotan klorpirifos yang dilakukan oleh petani sebanyak 2-3 kali sekitar 25-30 hari menjelang panen dapat menyebabkan tingginya residu klorpirifos. Sedangkan waktu paruh yang dibutuhkan klorpirifos untuk terurai dalam tanah yaitu 60-120 hari.Hal ini dapat menjadi faktor terdeteksinya klorpirifos pada beras (10).

Klorpirifos terserap (terabsorbsi) secara kuat ke dalam tanah dan tidak langsung terlepas karena sifat alami klorpirifos yang non-polar sehingga memiiliki kelarutan yang rendah dalam air dan di alam memiliki kecenderungan untuk membagi fase dari fase air ke fase organik (11).

Residu pestisida hasil pertanian dapat diatasi pada tahap prapanen maupun pasca panen.Metode pengurangan residu pestisida prapanen dapat dilakukan dengan menggunakan agen pengendali hayati (APH), penggunaan pestisida yang tidak persisten, penyemprotan yang dilakukan jauh hari sebelum panen, serta penggunaan arang aktif.Sedangkan untuk tahap pasca panen dapat dilakukan dengan pencucian, perendaman dengan air panas, dan lain-lain (12).

Klorpirifos menimbulkan efek pada serangga, mamalia dan manusia melalui penghambatan enzim asetilkolinestrase. 
Klorpirifos ini diabsorbsi secara cepat melalui inhalasi, oral, kulit dan mata. Setelah diabsorbsi sebagian besar akan diekskresikan melalui urin dan sisanya diubah menjadi metabolit klorpirifos oxon yang beracun. Setelah masuk ke dalam tubuh klorpirifos oxon akan mengikat enzim asetilkolinesterase (AChe) secara irreversibel, sehingga AChe menjadi inaktif dan terjadi akumulasi asetilkolin. AChe secara normal menghidrolisis asetilkolin menjadi asetat dan kolin. Pada saat AChe dihambat, jumlah asetilkolin meningkat dan berikatan dengan reseptor muskarinik dan nikotinik pada sistem saraf pusat dan perifer.Hal ini menyebabkan timbulnya gejala keracunan seperti sakit kepala, pusing, mual, muntah, pupil mengecil sehingga pengelihatan menjadi kabur, air liur berlebih, keringat berlebih, detak jantung sangat cepat dan otot tidak dapat digerakkan (5).

Pada paparan dosis rendah, tanda dan gejala umumnya dihubungkan dengan stimulasi reseptor perifer muskarinik dan pada dosis yang lebih besar akan mempengaruhi reseptor nikotinik dan reseptor sentral muskarinik. Aktivitas ini akan menurun dalam 2-4 minggu pada plasma dan 4 minggu sampai beberapa bulan untuk eritrosit (5).

\section{KESIMPULAN}

Berdasarkan penelitian yang telah dilakukan, diketahui bahwa kadar residu pestisida klorpirifos pada sampel beras A, B dan C yang berasal dari Kecamatan Baebunta, Kabupaten Luwu memiliki kadar di bawah nilai BMR $(0,5 \mathrm{mg} / \mathrm{kg})$ yang ditetapkan SNI sehingga ketiga sampel tersebut aman untuk dikonsumsi.

\section{DAFTAR PUSTAKA}

1. Badan pusat statistik. Distribusi perdagangan komuditas cabai merah Badan Pusat Statistik. 2017. Pengeluaran untuk Konsumsi Penduduk Indonesia per provinsi. Jakarta.

2. Widiarta, I.N. dan Suharto, H. 2009. Pengendalian Hama dan Penyakit Tanaman Padi Secara Terpadu. Badan Penelitian dan Pengembangan Pertanian-Balitbangtan. 441-442.

3. Balingtan. 2013. Teknologi menurunkan residu pestisida di lahan pertanian

(Online).(http://balingtan.litbang.pertanian.go.id/ind/index.php/berit a/138-teknologi menurunkan-residu-pestisida-di-lahan-pertanian, Diakeses 8 juli 2019).

4. Puspitasari, D. W. dan Khaeruddin. 2016. Kajian Bioremediasi pada Tanah Tercemar Pestisida. KOVALEN. 2(3):98-106

5. Runia, Y.A. 2008. Faktor-Faktor yang Berhubungan dengan Keracunan Pestisida Organofosfat, Karbamat dan Kejadian Anemia pada Petani Hortikultura di Desa Tejosari Kecamatan Ngablak Kabupaten Megelang. Tesis tidak diterbitkan. Semarang. Program Pascasarjana Universitas Diponegoro Semarang.

6. Badan Standarisasi Nasional. 2008. Batas Maksimum Residu Pestisida Pada Hasil Pertanian. SNI 7313:2008, ICS 65.100.01. BadanStandarisasi Nasional. Jakarta. Hal. 80.

7. Anastassiades, M., Lehotay, S.J., Stajnbaher, D.and Schenck, F.J. 2003. Fast and Easy Multiresidue Method Employing Acetonitrile Extraction/Partitioning and "Dispersive Solid-Phase Extraction" for The Determination of Pesticide Residues in Produce. Journal of AOAC International. 86:412-431

8. Mastovska, K., and Lehotay, S.J. 2004. Evaluation of Common Organic Solvents for Gas Chromatographic Analysis and Stability of Multiclass Pesticide Residues. Journal of Chromatography A, 1040: 259-272.

9. Lee SR, Mourer CR, Shibamoto T. 1991. Analysis before and after cooking processes of a trace chlorpyrifos spiked in polished rice. J Agric Food Chem 39:906-908

10. Anonim, 2001. Pedoman Cara Penggunaan Pestisida dengan Residu Minimum. Direktorat perlindungan Hortikultura, Direktorat Jendral Bina Produksi Horttikultura, Departemen Pertanian RI.Jakarta.

11. World Health Organization (WHO). 2004. Who Specifications and Evaluations for Public Health Pesticides, Chlorpyrifos (0,0-diethyl 03,5,6-trichloro-2-pyridyl phosphorothioate).

12. Fitriadi, B.R. dan Putri, A.C., 2016. Metode-metode Pengurangan Residu Pestisida pada Hasil Pertanian. Jurnal Rekayasa Kimia dan Lingkungan. 11(2):61-71. 